Acknowledgements: This study was sponsored by Biogen (Cambridge, MA, USA). Writing and editorial support was provided by Excel Scientific Solutions (Fairfield, CT, USA); funding was provided by Biogen.
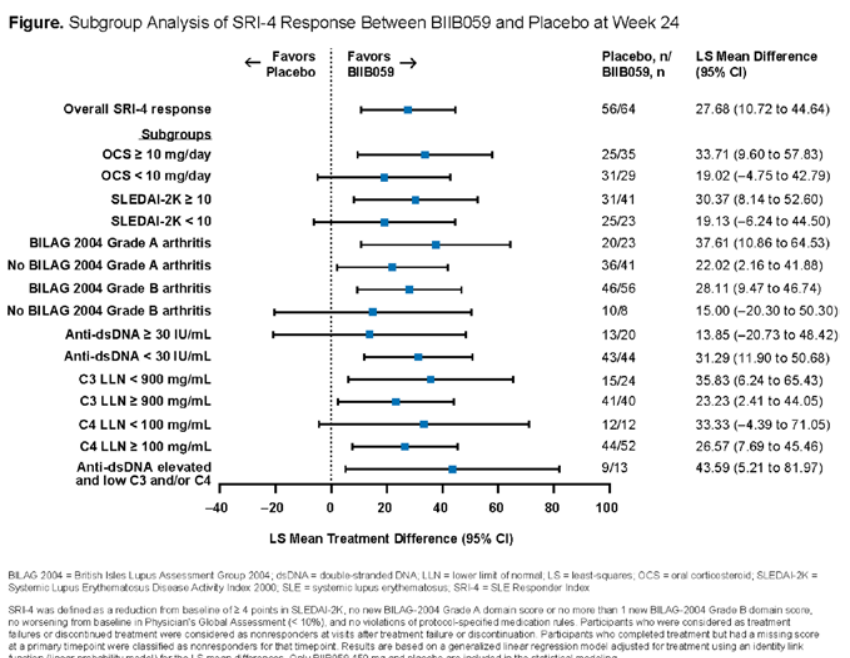

Disclosure of Interests: Ronald van Vollenhoven Consultant of: AbbVie, AstraZeneca, Biotest, Bristol Myers Squibb, Celgene, GlaxoSmithKline, Janssen, Lilly, Medac, Merck, Novartis, Pfizer, Roche, UCB, Grant/research support from: AbbVie, Arthrogen, Bristol Myers Squibb, GlaxoSmithKline, Lilly, Pfizer, UCB, Richard Furie Consultant of: Biogen, Grant/research support from: Biogen, Kenneth Kalunian Consultant of: AbbVie, Amgen, AstraZeneca, Biogen, Bristol Myers Squibb, Eli Lilly, Equillium, Genentech, Gilead, ILTOO, Janssen, Nektar, Roche, Viela, Grant/research support from: Lupus Research Alliance, Pfizer, Sanford Consortium, Sandra Navarra Speakers bureau: Astellas, Johnson \& Johnson, Novartis, Pfizer, Consultant of: Biogen, Grant/ research support from: Biogen, Juanita Romero-Diaz Consultant of: Biogen, Boehringer Ingelheim, Victoria Werth Consultant of: AbbVie, Amgen, AstraZeneca, Biogen, Bristol Myers Squibb, Eli Lilly, EMD Serono, Gilead, GlaxoSmithKline, Janssen, Kyowa Kirin, Resolve, Viela, Grant/research support from: Biogen, Celgene, Gilead, Janssen, Viela, XIAOBI HUANG Shareholder of: Biogen, Employee of: Biogen, HUA CARROLL Shareholder of: Biogen, Employee of: Biogen, Cristina Musselli Shareholder of: Biogen, Employee of: Biogen, Catherine Barbey Shareholder of: Biogen, Employee of: Biogen, NATHALIE FRANCHIMONT Shareholder of: Biogen, OMass Therapeutics, Employee of: Biogen

DOI: 10.1136/annrheumdis-2021-eular.2570

\section{POS0699 \\ GREATER REDUCTION IN CLASI-A SCORES ACHIEVED WITH BIIB059 VERSUS PLACEBO INDEPENDENTLY OF DISEASE SEVERITY AT BASELINE}

V. Werth ${ }^{1,2}$, R. Furie ${ }^{3}$, K. Kalunian ${ }^{4}$, R. Van Vollenhoven ${ }^{5}$, S. Navarra ${ }^{6}$, F. Nyberg ${ }^{7}$, J. Romero-Diaz ${ }^{8}$, M. Tee ${ }^{9}$, X. Huang ${ }^{10}$, H. Carroll ${ }^{11}$, C. Barbey ${ }^{12}$ C. Mussellii ${ }^{13}$, N. Franchimont ${ }^{13} .{ }^{1}$ University of Pennsylvania, Dermatology, Philadelphia, United States of America; ${ }^{2}$ Corporal Michael J. Crescenz VA Medical Center, Department of Dermatology, Philadelphia, United States of America; ${ }^{3}$ Northwell Health, Division of Rheumatology, Great Neck, United States of America; ${ }^{4}$ University of California San Diego", Division of Rheumatology, Allergy and Immunology, La Jolla, United States of America; ${ }^{5}$ Amsterdam University Medical Centers, Department of Rheumatology and Clinical Immunology, Amsterdam, Netherlands; ${ }^{6}$ University of Santo Tomas, Rheumatology, Manila, Philippines; ${ }^{7}$ Karolinska University Hospital, Department of Medicine, Stockholm, Sweden; ${ }^{8}$ Salvador Zubirán National Institute of Health Sciences and Nutrition, Department of Immunology and Rheumatology, Mexico City, Mexico; ${ }^{9}$ Medical Center Manila, College of Medicine, Manila, Philippines; ${ }^{10}$ Biogen, Biostatistics, Cambridge, United States of America; ${ }^{11}$ Biogen, Medical Evaluation/Global Safety, Cambridge, United States of America; ${ }^{12}$ Biogen, Clinical Development, Baar, Switzerland; ${ }^{13}$ Biogen, Clinical Development, Cambridge, United States of America

Background: Patients with cutaneous lupus erythematosus (CLE) experience symptoms including photosensitivity, rash, pain, and skin damage that can impact their quality of life. No targeted therapies are approved for CLE. BIIB059 is a humanized monoclonal antibody that targets blood dendritic cell antigen-2 (BDCA2), expressed exclusively on the surface of plasmacytoid dendritic cells (pDCs). The binding of BIIB059 to BDCA2 leads to rapid internalization of $\mathrm{BDCA} 2$ from the cell surface of $\mathrm{pDCs}$, thereby inhibiting the production of pDC-derived type I interferons, cytokines, and chemokines, which are involved in CLE pathology. In Part B of the 2-part, phase 2 LILAC study (NCT02847598), the primary endpoint was met: BIIB059 significantly reduced CLE activity, as evidenced by a statistically significant dose response and statistically significant differences in least-squares mean percent changes in Cutaneous Lupus Erythematosus Disease Area and Severity Index - Activity (CLASI-A) score versus placebo. $^{2}$

Objectives: To determine the proportion of patients with CLE who presented at baseline with moderate or severe disease (CLASI-A $\geq 10$ ) or with the higher category of mild disease (CLASI-A $<10$ [i.e., 8 or 9]) and experienced a shift in CLASI-A score to a mild skin disease category or clear/almost clear skin status.

Methods: Adults with histologically confirmed CLE with or without systemic manifestations were enrolled if they had CLASI-A $\geq 8$ at baseline, despite prior use of or intolerance to topical corticosteroids (CS) and/or antimalarials, in addition to $\geq 1$ lesion diagnostic of subacute CLE (CLASI-A erythema score $\geq 2$ ) and/ or chronic CLE (CLASI-A erythema score $\geq 2$ and CLASI-Damage scarring score $\geq 1$ ). Concomitant CLE/SLE therapy was allowed if doses were initiated $\geq$ 12 weeks and kept stable $\geq 4$ weeks before randomization and throughout the treatment period. Systemic corticosteroid doses could not exceed $15 \mathrm{mg} /$ day of prednisone (or equivalent). BIIB059 (50,150, $450 \mathrm{mg}$ ) or placebo was subcutaneously administered once every 4 weeks for 12 weeks, with an additional dose at Week 2. An ad hoc analysis was conducted to determine the proportion of participants (CLASI-A $\geq 10$ or $<10$ at baseline) with a shift in CLASI-A score to $\leq$ $1, \leq 3, \leq 6$, and $\leq 8$ at Week 16

Results: In this ad hoc analysis from LILAC Part B, 106 (80.3\%) and 26 (19.7\%) of participants had a baseline CLASI-A score $\geq 10$ and $<10$, respectively. Compared with placebo, higher proportions of participants treated with BIIB059 achieved a shift in CLASI-A score from either $\geq 10$ or $<10$ at baseline to $\leq 1, \leq 3, \leq 6$, and $\leq 8$ at Week 16 (Figure 1). Treatment with BllB059 resulted in higher proportions of participants achieving reduced scores, indicating shifts to more mild disease activity, compared with placebo. A score $\leq$ 1 (clear or almost clear skin) at Week 16 was achieved by $0.0 \%(0 / 25), 5.0 \%$ $(1 / 20), 14.3 \%(3 / 21)$, and $12.5 \%(5 / 40)$ of participants with baseline CLA$\mathrm{SI}-\mathrm{A} \geq 10$ who were treated with placebo and BIIB059 50, 150, and $450 \mathrm{mg}$, respectively. Two of 26 participants with baseline CLASI-A $<10$ achieved a score $\leq 1$ (both received BIIB059 $150 \mathrm{mg}$ ).

Conclusion: A greater proportion of participants achieved milder skin disease or clear/almost clear skin status in the BIIB059 groups as compared with the placebo group. This effect was observed in participants with moderate or severe disease as well as in those in the higher range of the mild category of disease severity at baseline, indicating the ability of BIIB059 to improve skin lesions in patients with a broad range of cutaneous disease activity.

\section{REFERENCES:}

[1] Albrecht J, et al. J Invest Dermatol. 2005;125(5):889-894.

[2] Werth V, et al. Arthritis Rheumatol. 2020;72(suppl 10). Abstract 0986.

Figure. Percentage of Participants With Baseline CLASI-A $\geq 10$ and $<10$ Achieving a Decrease to CLASI-A Score Thresholds $\leq 1, \leq 3, \leq 6$, and $\leq 8$ at Week 16

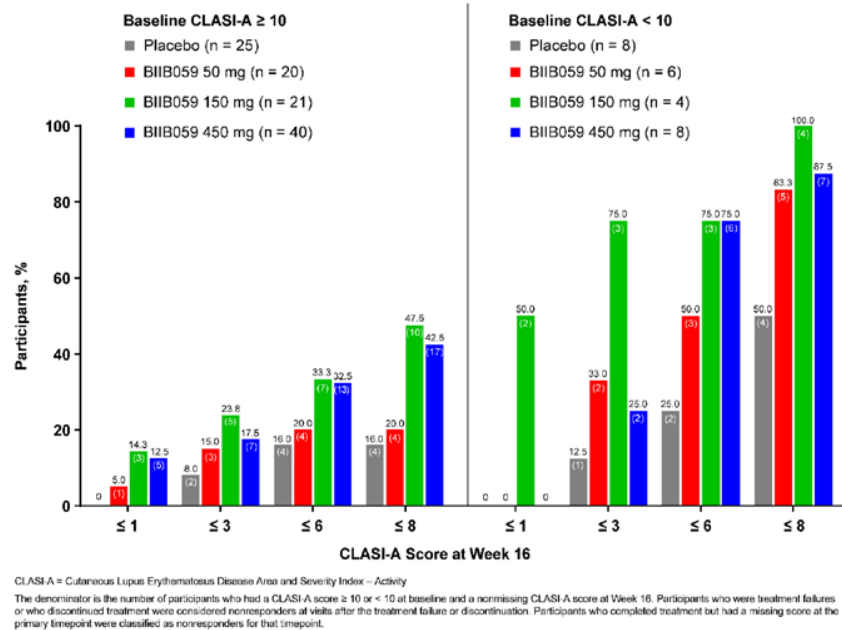


Acknowledgements: This study was sponsored by Biogen (Cambridge, MA, USA). Writing and editorial support was from Excel Scientific Solutions (Fairfield, CT, USA); funding was provided by Biogen.

Disclosure of Interests: Victoria Werth Consultant of: AbbVie, Amgen, AstraZeneca, Biogen, Bristol Myers Squibb, Eli Lilly, EMD Serono, Gilead, GlaxoSmithKline, Janssen, Kyowa Kirin, Resolve, Viela, Grant/research support from: Biogen, Celgene, Gilead, Janssen, Viela, Richard Furie Consultant of: AstraZeneca, Biogen, Grant/research support from: AstraZeneca, Biogen, Kenneth Kalunian Consultant of: AbbVie, Amgen, AstraZeneca, Biogen, Bristol Myers Squibb, Eli Lilly, Equillium, Genentech, Gilead, ILTOO, Janssen, Nektar, Roche, Viela, Grant/research support from: Lupus Research Alliance, Pfizer, Sanford Consortium, Ronald van Vollenhoven Consultant of: AbbVie, AstraZeneca, Biotest, Bristol Myers Squibb, Celgene, GlaxoSmithKline, Janssen, Lilly, Medac, Merck, Novartis, Pfizer, Roche, UCB, Grant/research support from: AbbVie, Arthrogen, Bristol-Myers Squibb, GlaxoSmithKline, Lilly, Pfizer, UCB, Sandra Navarra Speakers bureau: Astellas, Johnson \& Johnson, Novartis, Pfizer, Consultant of: Biogen, Filippa Nyberg Consultant of: Biogen, Juanita Romero-Diaz Consultant of: Biogen, Boehringer Ingelheim, Michael Tee Speakers bureau: Pfizer, Novartis, Johnson \& Johnson, Celltrion, Consultant of: Neovacs, Grant/ research support from: Celltrion, Johnson \& Johnson, Pfizer, XIAOBI HUANG Shareholder of: Biogen, Employee of: Biogen, HUA CARROLL Shareholder of: Biogen, Employee of: Biogen, Catherine Barbey Shareholder of: Biogen, Employee of: Biogen, Cristina Musselli Shareholder of: Biogen, Employee of: Biogen, NATHALIE FRANCHIMONT Shareholder of: Biogen, OMass Therapeutics, Employee of: Biogen

DOI: 10.1136/annrheumdis-2021-eular.2716

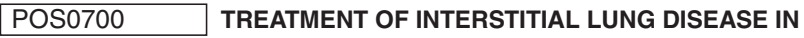 PATIENTS WITH PRIMARY SJOGREN SYNDROME: A SINGLE-CENTER RETROSPECTIVE ANALYSIS}

T. Y. Lan ${ }^{1}$, H. T. Huang ${ }^{2}$, J. H. Kao', C. F. Cheng3, C. H. Lu3, C. Y. Shen3, K. J. Li3, S. C. Hsieh ${ }^{1} .{ }^{1}$ National Taiwan University Hospital, Department of Internal Medicine, Rheumatology Division, Taipei, Taiwan, Republic of China: ${ }^{2}$ National Taiwan University Hospital, Department of Oncology, Taipei, Taiwan, Republic of China; ${ }^{1}$ National Taiwan University Hospital, Department of Internal Medicine, Rheumatology Division, Taipei, Taiwan, Republic of China

Background: Interstitial lung disease (ILD) is one of the main contributor to morbidity and mortality in patients with primary Sjogren syndrome (pSS), and whether immunosuppressive treatments are effective for pSS-ILD is uncertain. Cyclophosphamide (CYC) and rituximab (RTX) are effective in stabilizing pulmonary function in patients with ILD caused by systemic sclerosis, inflammatory myositis, and rheumatoid arthritis ${ }^{1,2}$. Reports regarding the treatment response for cyclophosphamide or rituximab in pSS-ILD patients are lacking.

Objectives: To investigate whether add-on CYC or RTX in addition to steroid and oral DMARDs leads to greater improvement in pulmonary function test than conventional treatment in patients with pSS-ILD with impaired baseline pulmonary function.

Methods: pSS-ILD patients with ILD confirmed by a chest computed tomography were screened. Those with imparied baseline pulmonary function test (FVC $<80 \%$ and DLCO $<80 \%$ ) and available results of pulmonary function tests at 6th-18th month post-treatment were retrospectively enrolled. The patients were clustered into two groups: steroid and oral DMARDs alone (steroid/oDMARD group), and add-on CyC and/or RTX (Add-on CyC/RTX group).

Results: This study enrolled 22 patients. The median age of these patients was 65 . Among them, $68 \%$ were female and $18 \%$ were smokers. The median baseline FVC was $63.5 \%$ and the median DLCO was $54.4 \%$. The predominant CT pattern was NSIP (54\%), followed by UIP (22\%), LIP (13.6\%) and OP $(9 \%)$ (table 1).

Five patients received steroid and oral DMARDs alone (hydroxychloroquine +/azathioprine), while 17 patients received add-on CYC and/or RTX (8 patients received CYC, 3 received $\mathrm{RTX}$, and 6 received CYC and RTX). There was no significant difference in baseline characteristic between these two groups (table 1).

With a median follow-up period of 9.8 months (interquartile range $7.6-13.4$ months) after treatment, the FVC improved significantly from $61.3 \%$ to $65.5 \%$ $(p=0.013)$ in CYC/RTX group, while the FVC improvement was not significant in steroid/oDMARD group (figure 1A). In CYC/RTX group, patients with nonUIP pattern (NSIP, LIP and OP) on chest CT had significant FVC improvement $(p=0.021)$, contrasting to the patients with UIP pattern on chest CT (figure 1B).

Conclusion: In pSS patients with ILD and impairment of pulmonary function at baseline (FVC $<80 \%, \mathrm{DLCO}<80 \%$ ), FVC improved significantly in patients received add-on cyclophosphamide and/or rituximab therapy.

\section{REFERENCES:}

[1] Wells AU, Denton CP. Interstitial lung disease in connective tissue disease--mechanisms and management. Nat Rev Rheumatol. 2014 Dec;10(12):728-39.

[2] Gao Y, Moua T. Treatment of the Connective Tissue Disease-Related Interstitial Lung Diseases: A Narrative Review. Mayo Clin Proc. 2020 Mar;95(3):554-573.

Table 1. Baseline characteristics of patients with Sjögren's syndrome and interstitial lung disease

\begin{tabular}{|c|c|c|c|c|}
\hline & $\begin{array}{l}\text { Total } \\
(n=22)\end{array}$ & $\begin{array}{l}\text { Steroid/oDMARDs } \\
(n=5)\end{array}$ & $\begin{array}{l}\text { s Add-on CYC/ } \\
\text { RTX } \\
(n=17)\end{array}$ & $\begin{array}{l}\text { Comparison } \\
\text { between two } \\
\text { groups ( } p \text {-value) }\end{array}$ \\
\hline Age, year, median (IQR) & $\begin{array}{c}65.1(61.7 \\
-69.1)\end{array}$ & $64(64.6-67.4)$ & $\begin{array}{c}65.6(61.6 \\
-69.2)\end{array}$ & 0.88 \\
\hline Female sex, n (\%) & $15(68 \%)$ & $4(80 \%)$ & $12(70 \%)$ & 1.00 \\
\hline Smoking, n (\%) & $4(22 \%)$ & $0(0 \%)$ & $4(21 \%)$ & 0.54 \\
\hline $\begin{array}{l}\text { Baseline } \mathrm{FVC}, \% \text { of } \\
\text { predicted value, median } \\
\text { (IQR) }\end{array}$ & $\begin{array}{c}63.6 \%(53.8 \\
-68.2)\end{array}$ & $63.9 \%(63.7-67.5)$ & $\begin{array}{c}61.3 \%(50.2 \\
-68.2)\end{array}$ & 0.43 \\
\hline $\begin{array}{l}\text { Baseline DLCO, \% of } \\
\text { predicted value, median } \\
\text { (IQR) }\end{array}$ & $\begin{array}{l}54.4 \%(39.4 \\
-66.4)\end{array}$ & $69.1 \%(57.8-75.5)$ & $\begin{array}{c}52.1 \%(38.5 \\
-58.1)\end{array}$ & 0.12 \\
\hline \multicolumn{4}{|l|}{ CT pattern, n (\%) } & - \\
\hline & $\begin{array}{c}(54 \%) \\
\text { UIP - } 5(22 \%) \\
\text { LIP - } 3 \\
(13.6 \%) \\
\text { OP }-2(9 \%)\end{array}$ & $\begin{array}{l}\text { UIP } 1(20 \%) \\
\text { LIP } 2(40 \%) \\
\text { OP } 1(20 \%)\end{array}$ & $\begin{array}{l}(65 \%) \\
\text { UIP - } 4(24 \%) \\
\text { LIP - } 1(6 \%) \\
\text { OP - } 1(6)\end{array}$ & \\
\hline UIP pattern, n (\%) & $5(22 \%)$ & $1(20 \%)$ & $4(24 \%)$ & 1.00 \\
\hline
\end{tabular}

CYC, cyclophosphamide; oDMARDs, oral DMARDs; RTX, rituximab
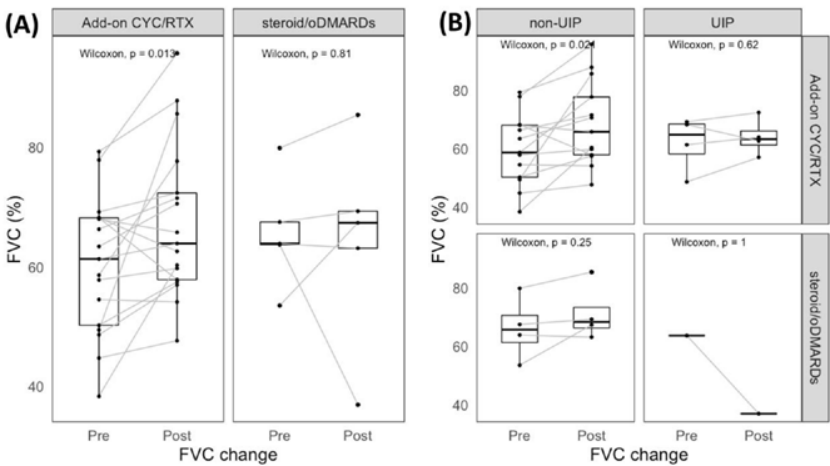

Figure 1. FVC change before and after the immunosuppressive treatment

Disclosure of Interests: None declared DOI: 10.1136/annrheumdis-2021-eular.2758 